\title{
Risk factors for death and temporal trends in overall survival in patients with AIDS-associated primary central nervous system lymphoma (AIDS-PCNSL)
}

Thomas S Uldrick ${ }^{1 *}$, Sharon Pipkin ${ }^{2}$, Susan Scheer ${ }^{2}$, Nancy A Hessol ${ }^{3}$

From 13th International Conference on Malignancies in AIDS and Other Acquired Immunodeficiencies (ICMAOI)

Bethesda, MD, USA. 7-8 November 2011

\section{Background}

AIDS-PCNSL is a rare EBV-associated B-cell neoplasm that continues to carry a poor prognosis, even in the highly active antiretroviral therapy (HAART) era. We hypothesized that overall survival (OS) is affected by prior diagnosis of central nervous system (CNS) infections as well as treatment approaches to both HIV and AIDS-PCNSL. We evaluated risk factors and temporal trends for OS in patients with AIDS-PCNSL.

\section{Methods}

Adults with AIDS-PCNSL were identified through a computer linkage that matched AIDS case diagnosed between 1990-2000 from the San Francisco adult AIDS case registry with the California Cancer Registry (19852002), with mortality follow-up through $12 / 31 / 2007$.
Patients with non-B-cell histology or history of systemic non-Hodkgin lymphoma diagnosed within 2 years prior to AIDS-PCNSL diagnosis were excluded. Prognostic factors evaluated include: diagnosis of CNS infection prior to AIDS-PCNSL, diagnosis of other common opportunistic infection (OI) prior to AIDS-PCNSL (pneumocystis pneumonia $[\mathrm{PCP}]$ or mycobacterium avium complex [MAI]), pathologic versus clinical diagnosis, receipt of cancer therapy, HAART prescribed prior to or within 30 days of AIDS-PCNSL diagnosis, and year of diagnosis (1990-1995, 1996-1998, 1999-2002). Survival analyses employed Kaplan-Meier methodology.

\section{Results}

A total of 207 patients were identified, 96\% male and 4\% female. Median age 39 (IQR 35-46), 68\% white, 21\%

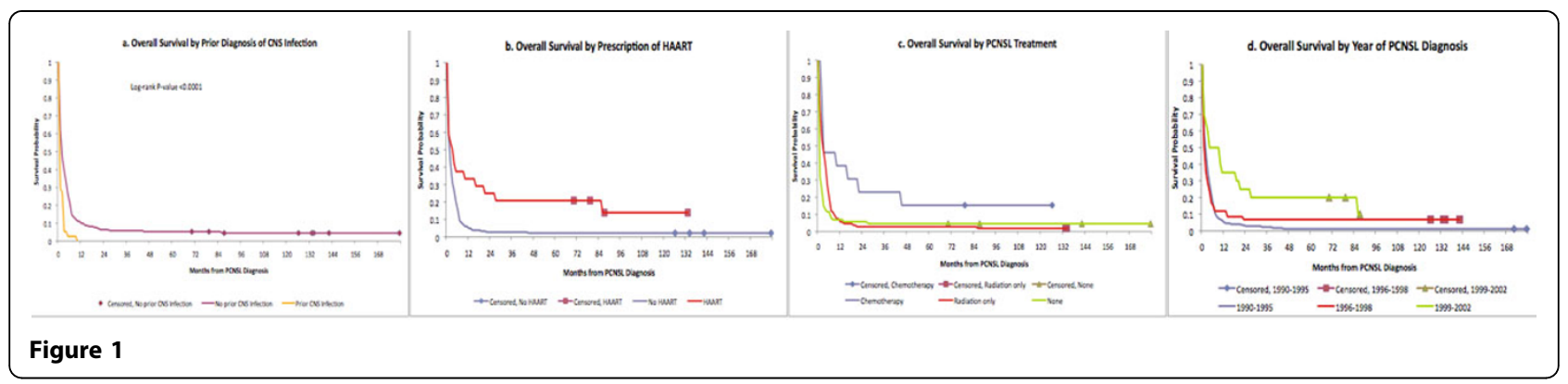

\footnotetext{
* Correspondence: uldrickts@mail.nih.gov

${ }^{1}$ HIV \& AIDS Malignancy Branch, Center for Cancer Research, National Cancer Institute, National Institutes of Health, Bethesda, MD, USA

Full list of author information is available at the end of the article
}

(c) 2012 Uldrick et al; licensee BioMed Central Ltd. This is an open access article distributed under the terms of the Creative Commons 
black, 20\% Hispanic, 2\% Asian. Median CD4 20 cells/uL (IQR 6-53). HIV risk group: 79\% MSM, 8\% IDU, 9\% MSM/IDU. CNS infections prior to AIDS-PCNSL: toxoplasmosis $8 \%$, cryptococcus $9 \%$, histoplasmosis $1 \%$, extrapulmonary tuberculosis $1 \%$. Treatment category: none $42 \%$, radiation only $52 \%$, chemotherapy $6 \%$ (5/13 chemotherapy only, 6/13 chemotherapy and radiation, $2 / 13$ chemotherapy and immunotherapy). Risk factors for OS included prior CNS infection $(\mathrm{p}<0.0001)$, HAART $(\mathrm{p}=0.0023)$, AIDS-PCNSL treatment $(\mathrm{p}<0.0001)$, and calendar period of AIDS-PCNSL diagnosis (0.001), but not prior PCP or MAC $(\mathrm{p}=0.23)$. (Figures 1 A-D.) OS was improved by HAART across treatment groups $(\mathrm{p}<0.0001)$.

\section{Conclusions}

Prior diagnosis of CNS infection, HAART, and cancer treatment are strong predictors of OS. OS improved over time in these patients. Earlier diagnosis of AIDSPCNSL and/or CNS infection, treatment of CNS infections, and cancer treatment that includes HAART and concomitant chemotherapy may increase AIDS-PCNSL survival. Prospective evaluation of curative-intent chemotherapy-based approaches to AIDS-PCNSL is urgently needed. Additional analyses are ongoing.

\section{Author details}

${ }^{1}$ HIV \& AIDS Malignancy Branch, Center for Cancer Research, National Cancer Institute, National Institutes of Health, Bethesda, MD, USA. ${ }^{2}$ San Francisco Department of Public Health, San Francisco, CA, USA. ${ }^{3}$ Departments of Clinical Pharmacy \& Medicine, University of California, San Francisco, CA, USA

Published: 19 April 2012

doi:10.1186/1750-9378-7-S1-018

Cite this article as: Uldrick et al:: Risk factors for death and temporal trends in overall survival in patients with AIDS-associated primary central nervous system lymphoma (AIDS-PCNSL). Infectious Agents and Cancer 2012 7(Suppl 1):018.
Submit your next manuscript to BioMed Central and take full advantage of:

- Convenient online submission

- Thorough peer review

- No space constraints or color figure charges

- Immediate publication on acceptance

- Inclusion in PubMed, CAS, Scopus and Google Scholar

- Research which is freely available for redistribution

Submit your manuscript at www.biomedcentral.com/submit 